\title{
Influence of display type and cue format on task-cuing effects: Dissociating switch cost and right-left prevalence effects
}

\author{
Robert W. Proctor \\ Purdue University, West Lafayette, Indiana \\ IRING KOCH \\ RWTH Aachen University, Aachen, Germany \\ KIM-PhuONG L. VU \\ California State University, Long Beach, California \\ AND \\ Motonori YAMAGUCHI \\ Purdue University, West Lafayette, Indiana
}

\begin{abstract}
In previous studies of task switching and of the right-left prevalence effect, researchers have used a procedure in which the stimulus on each trial occurs in one of four quadrants, and responses are made by pressing one of two diagonally arranged response keys. Across these studies, discrepant effects of cuing interval have been reported. These discrepancies need clarification because cue-based preparation effects are frequently interpreted as reflecting cognitive control processes. In Experiment 1, we compared performance with display formats used by Meiran (1996; Meiran, Chorev, \& Sapir, 2000; small display, cues located at sides of quadrants and displayed until response) to study task switching and by Proctor and colleagues (Proctor, Koch, \& Vu, 2006; large display, cues located at center of display and shown until target onset) to study right-left prevalence. We found a decrease in taskswitch cost with increasing cuing interval with the Meiran display, but not with the Proctor display, but the right-left prevalence effect was of similar size for the two display formats and was relatively unaffected by cuing interval. To determine the basis of the discrepant task-switch results, we used small and large displays in Experiments 2 and 3, respectively, with cue type and cue offset varied. With the side cues, the task-switch cost decreased in all cases at the longer cuing interval, but with the centered cues, it decreased only when the display size was small. Thus, the effects of cuing interval on switch costs are sensitive to variations of display characteristics, whereas cuing interval and display characteristics have little influence on the right-left prevalence effect, suggesting that prevalence effect is due to processes that are independent from those producing the switch cost.
\end{abstract}

When stimuli and responses are arrayed in four quadrants of a real or imaginary square, each location can be represented on two dimensions: horizontal and vertical. Two-dimensional arrays have been used in order to investigate issues concerning switching between tasks for which the horizontal or vertical dimension is defined as relevant (e.g., Meiran, 1996), as well as issues of whether maintaining stimulus-response (S-R) compatibility (i.e., correspondence of stimuli and their assigned response locations) is more important along the vertical or horizontal dimension (e.g., Rubichi, Vu, Nicoletti, \& Proctor, 2006). In both lines of research, participants are cued or instructed to respond along one dimension and ignore the other. Task-switching studies show robust switch costs, whereas compatibility studies typically show a right-left prevalence effect. However, despite the structural similarities of the experimental designs, and although some similar results have been obtained in the tasks used for investigating task switching and right-left prevalence, the results have not been entirely consistent.

In particular, manipulations of cuing intervals in taskswitching studies have shown that a long cuing interval (time between cue onset and onset of the target stimulus) leads to shorter reaction time (RT) and reduced switch costs than does a short cuing interval. These cuing interval effects have been interpreted as being a signature of advance preparation, which is an important aspect of cognitive control (see, e.g., Meiran, 1996; Monsell, 2003). In contrast, manipulations of cuing interval in compatibility studies have found no clear reduction of the right-left

R.W.Proctor, proctor@psych.purdue.edu 
prevalence effect or of switch costs, and sometimes even longer RT at long cuing intervals than at short cuing intervals (Proctor, Koch, \& Vu, 2006, Experiment 2). In the present study, we examine these discrepancies in effects of cuing interval.

Task switching was studied by Meiran (1996; Meiran, Chorev, \& Sapir, 2000) with a display that consisted of a $2 \times 2$ grid, in which the target stimulus could appear in one of the four quadrants. The responses were arrayed diagonally along the positive (" 1 " and "9" keys) or negative ("7" and " 3 " keys) axis of the numeric keypad of a computer keyboard. Prior to onset of the target stimulus, two outward-pointing arrowheads were presented outside the central vertical or horizontal axis in order to signal that responses should be based on the vertical or horizontal dimension, respectively. With this arrangement, stimuli presented in locations along the same diagonal as the responses required the same response, regardless of which dimension was cued (rule-congruent trials). In contrast, stimuli presented along the diagonal opposite that of the responses required a different response to be made to each cued dimension (rule-incongruent trials). Meiran (1996, Experiments 1 and 2) found that RT was shorter when the task repeated than when it switched, and this switch cost (or repetition benefit) decreased more at long cuing intervals than at short ones. Rule congruency did not interact significantly with either task repetition/switch or cuing interval in these experiments, although both experiments showed tendencies for larger switch costs at the short cue-target interval for rule-incongruent trials than for rule-congruent trials. Meiran (1996) interpreted the task-switch cost and its reduction at longer cuing intervals as indicating that a time-consuming, effortful reconfiguration of task set is necessary when the task switches (see also Rogers \& Monsell, 1995).

Compatibility effects on the vertical and horizontal dimensions were studied by $\mathrm{Vu}$ and Proctor (2001) using a similar task, for which stimuli occurred in the four corners of the computer screen. Their participants were instructed to respond based on only one dimension or the other throughout a block of trials. Depending on the diagonal along which the stimuli and responses were arrayed in a given block, the mapping of stimuli to responses was compatible along one, both, or neither of the two dimensions. The results showed a right-left prevalence effect so that, when collapsed across instructions, performance was better when compatibility was maintained on the horizontal dimension, rather than on the vertical dimension. Although the right-left prevalence effect tends to be pervasive (e.g., Hommel, 1996; Nicoletti \& Umiltà, 1984, 1985), it can be eliminated and replaced with a topbottom prevalence effect when the vertical dimension is made salient by the stimulus and response environment (Vu \& Proctor, 2002). Findings such as these led Rubichi et al. (2006) to conclude that the prevalence effect is a consequence of the relative salience of the dimensions, as determined by the task structure.

In a recent study, Proctor et al. (2006) designed a paradigm that contained elements of both the task-switching and compatibility methods in order to examine whether the right-left prevalence effect is influenced by task switching. In their study, the relevant dimension on each trial was cued using a centered double arrow, oriented horizontally or vertically, and the stimuli were solid disks that could appear in one of the four corners of the screen. Proctor et al.'s (2006) Experiment 3 included both rule-congruent and rule-incongruent trials, as in Meiran's (1996) study, using only a compatible mapping condition. For different groups of participants, the cuing intervals of 100 and $900 \mathrm{msec}$ were varied in alternating blocks of trials or within a block of trials. Proctor et al. (2006) found an overall 13-msec right-left prevalence effect that did not interact with cuing interval or with blocked versus randomized presentation of the intervals, consistent with Rubichi et al.'s (2006) conclusion that the prevalence effect is a function of coding constraints imposed by the task structure. The prevalence effect did, however, interact with rule congruency: A significant right-left prevalence effect $(24 \mathrm{msec})$ was evident on rule-incongruent trials, but not on rule-congruent trials. This finding suggests that the advantage for horizontal location coding occurs primarily when the horizontal and vertical codes signal different responses.

However, Proctor et al.'s (2006) data showed no cuinginterval effects on switch costs, whereas Meiran (1996) reported robust cuing-interval effects on switch costs. Clarifying the basis for this discrepancy is important theoretically because cuing effects in task switching are typically interpreted as being the hallmark of executive control (e.g., Monsell, 2003). Moreover, a recent discussion in task switching assigns to cue-based processes a crucial role in the genesis of switch costs (e.g., Altmann, 2006; Gade \& Koch, 2007; Logan \& Bundesen, 2003; Mayr \& Kliegl, 2003; Schneider \& Logan, 2005). Yet the discrepancy in the results observed in Meiran's (1996) and Proctor et al.'s (2006) paradigms suggests that procedural aspects have a profound influence on task-cuing effects (see also Verbruggen, Liefooghe, Vandierendonck, \& Demanet, 2007). Thus, the present study explored factors that influence cuing effects across different procedural variants of the spatial task-switching paradigm.

Because Meiran's (1996; Meiran et al., 2000) studies were conducted mainly to examine effects of task switching, many of his results were not reported in a way that allows evaluation of the right-left prevalence effect; that is, the data were collapsed across whether the horizontal or vertical task was cued. Data from three of his experiments, though, were reported as a function of the task, or cue dimension (Meiran, 1996, Experiment 4; Meiran et al., 2000, Experiments 2 and 3). In Meiran's (1996) Experiment 4, the main effect of cue dimension was not significant, indicating no overall right-left prevalence effect. However, mean RT was 10 msec shorter for the right-left task than for the top-bottom task, with this difference being largest for rule-incongruent trials on which there was a task switch (34 msec at the short cue-target interval of $132 \mathrm{msec}$, and $19 \mathrm{msec}$ at the long cue-target interval of $1,632 \mathrm{msec}$ ). The main effect of cue dimension did reach statistical significance in Meiran et al.'s Experiments 2 and 3, with the right-left prevalence effects being 14 and $30 \mathrm{msec}$, respectively. In Meiran et al.'s Experiment 2, there was also a sig- 
nificant interaction of cue dimension with cuing interval, with the right-left prevalence effect being larger at short intervals than at longer ones (RT differences of 35 and $15 \mathrm{msec}$, at the shortest and longest cue-target intervals of approximately $100 \mathrm{msec}$ and $2 \mathrm{sec}$, respectively). Thus, across the experiments of Meiran (1996) and Meiran et al., a right-left prevalence effect was clearly present (see also Koch et al., 2003, who found a 26-msec prevalence effect), but whether the effect was influenced by cuing interval is less clear.

It is important to know whether there are conditions under which the right-left prevalence effect is reduced at long cuing intervals, because the vertical dimension might be expected on some accounts to benefit more than the horizontal dimension from advanced preparation. For example, according to a grouping model proposed by Adam, Hommel, and Umiltà (2003) to explain spatial precuing effects, response selection is based on groupings of stimulus locations and response locations in input and output buffers. These groupings are formed quickly and automatically when the relevant distinction is salient, as is the case for the horizontal dimension, but their formation is slow and effortful when the distinction is not salient, as is the case for the vertical dimension. Because vertical subgroups could be formed through effortful processing if the cuing interval were sufficiently long, the advantage for the horizontal dimension should be reduced - if not eliminated — at long cuing intervals. Thus, the present experiments also evaluated whether conditions exist for which the right-left prevalence effect is reduced at long cuing intervals.

In sum, there are two major discrepancies between Meiran's (1996; Meiran et al., 2000) findings and those of Proctor et al. (2006). Meiran (1996; Meiran et al., 2000) found a larger switch cost at short cuing intervals than at long ones, whereas Proctor et al. (2006) did not. In contrast, Meiran (1996; Meiran et al., 2000) found some evidence suggesting that the right-left prevalence effect may decrease at a long cuing interval, whereas Proctor et al. (2006) did not. Resolution of these discrepancies is necessary for understanding the theoretical implications of the joint findings of these studies for advance preparation. The purpose of the present study was, therefore, to clarify the basis for these discrepancies and to assess their theoretical implications. In Experiment 1, we replicated the specific conditions of Meiran's (1996; Meiran et al., 2000) and Proctor et al.'s (2006) experiments in order to determine whether both patterns of results could be obtained within a single experiment. In Experiments 2 and 3, we dissociated potentially critical variables differentiating their procedures - those of display size, cue type, and cue offset - in order to determine more specifically which factors determine the patterns of repetition/switch and right-left prevalence effects.

\section{EXPERIMENT 1}

\section{Method}

Participants. Ninety-six student volunteers were recruited from Purdue University's introductory psychology courses for credit toward their experimental participation requirement.

Apparatus and Stimuli. The program was written in Micro Experimental Laboratory (2.01) and run on a personal computer. Stimuli were presented on a 14-in. VGA monitor at a viewing distance of approximately $55 \mathrm{~cm}$.

One condition used a display format similar to that used by Proctor et al. (2006; see Figure 1A). The target stimuli were solid discs (1.5 cm diameter) arrayed in four locations along the major diagonals of an imaginary square (upper left, lower right, upper right, and lower left). The distance between the two target stimuli on the same diagonal was $21 \mathrm{~cm}$. The cues were double arrows $(1.25 \mathrm{~cm}$ long, with $0.7 \mathrm{~cm}$ wide arrowheads) oriented horizontally or vertically in order to signal the relevant dimension for a trial. Responses were arrayed along one of two diagonals of a numeric keypad of the computer keyboard ("7" and " 3 " keys or "9" and "1" keys), with half of the participants using one response diagonal for all trials, and half using the other. The leftmost key was operated by the left index finger, and the rightmost key by the right index finger.

In the other condition, the display format approximated that used by Meiran (1996; see Figure 1B). It consisted of a visible grid (3.4 $\times$ $3.4 \mathrm{~cm})$, for which the stimuli were filled disks $(0.5 \mathrm{~cm}$ diameter $)$ presented in the center of one of the four quadrants. The cues were two arrows $(0.6 \mathrm{~cm}$ long, with a 0.5 - $\mathrm{cm}$-wide arrowhead) presented to the left and right or top and bottom sides of the grid, $0.2 \mathrm{~cm}$ from the edge.

In each condition, short (203 msec) and long (1,423 msec) cuing intervals were varied between trial blocks. These values correspond to those used in Meiran's (1996) Experiment 1, but are somewhat
A

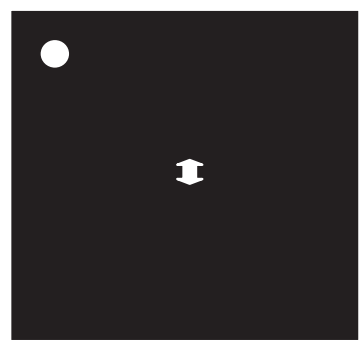

B

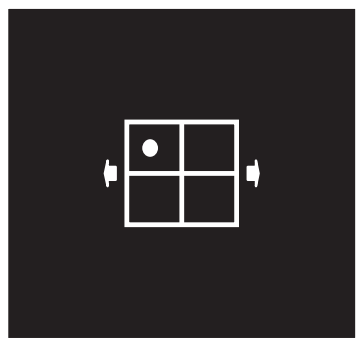

C

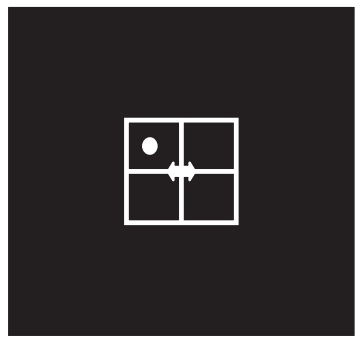

Figure 1. Illustrations of the displays used in Experiments 1 and 2. In Experiment 1, the display was similar to that of Proctor et al. (2006) in one condition (A), whereas it approximated the display used by Meiran (1996) in the other condition (B). In Experiment 2, the display was identical to the Meiran display condition of Experiment 1. However, in one display condition, the same side cues as in Experiment 1 were used (B), whereas the cue was a centered double-headed arrow in the other display condition (C). 
longer than those used in Proctor et al.'s (2006) study. The intertrial interval (or response-cue interval) was held constant at $1,138 \mathrm{msec}$. This length is slightly longer than the $1-\mathrm{sec}$ value that Meiran et al. (2000) determined would minimize any effects of response-cue interval. For the Proctor display format, the cue remained present for the cuing interval and offset simultaneously with onset of the target; for the Meiran display format, the cue was present for the cuing interval, but remained on the screen when the stimulus was presented, with both going off when a response was made. These procedures followed those of Proctor et al. (2006) and Meiran (1996), respectively.

Procedure. Participants were instructed to respond with a compatible S-R mapping along the cued dimension. If the cue was a left-right (horizontal) arrow, the left key was to be pressed to the left stimulus, and the right key to the right stimulus. If the cue was a top-down (vertical) arrow, the upper key was to be pressed to the top stimulus and the lower key to the bottom stimulus.

Participants performed eight blocks of 80 trials, with the cuing interval alternating between blocks. The cuing interval for the first block of trials was counterbalanced across participants. For half of the trials, the $\mathrm{S}-\mathrm{R}$ relation was incongruent for the two dimensionsthat is, compatible along the cued dimension and incompatible along the alternative dimension. For the other half, the $\mathrm{S}-\mathrm{R}$ relation was congruent - that is, compatible on both the cued and uncued dimensions. Each trial began with the onset of a cue and ended when the participant responded to the target stimulus; the next cue appeared after the intertrial (response-cue) interval.

\section{Results}

The first 10 trials in each block were excluded as warmup, as were trials with RTs less than $200 \mathrm{msec}$ or greater than 3,000 msec (2.3\% of the trials). Mean correct RT and percentage error (PE) were submitted to a five-factor ANOVA (see Table 1), the first factor of which was between participants: display format (Meiran, Proctor) $\times$ task transition (repetition, switch) $\times$ cue dimension (horizontal, vertical) $\times$ rule congruency (congruent, incongruent) $\times$ cuing interval (short, long). Means for each condition are shown in Table 2.

Mean RT was slightly longer for the Meiran display $(M=$ $569 \mathrm{msec})$ than for the Proctor display $(M=539 \mathrm{msec})$, but this difference was not significant $[F(1,94)=1.27, p=$ $.262]$. For the within-participants variables, main effects of task transition, cue dimension, and rule congruency were significant. Mean RT was 36 msec longer when the task switched $(M=572 \mathrm{msec})$ than when it repeated $(M=$ $536 \mathrm{msec}), 22 \mathrm{msec}$ longer when the cue dimension was vertical $(M=565 \mathrm{msec})$ than when it was horizontal $(M=$ $543 \mathrm{msec}$ ), and $84 \mathrm{msec}$ longer when the dimensions were incongruent $(M=596 \mathrm{msec})$ than when they were congruent $(M=512 \mathrm{msec})$. Thus, standard task-switch, right-left prevalence, and rule-congruency effects were obtained.

The cuing-interval effect was not significant $[F(1,94)=$ $3.14, p<.08$ ], but this variable entered into two-way interactions with display format and task transition, as well as a three-way interaction with both. With the Meiran display, mean RT was longer at the short cuing interval $(M=597 \mathrm{msec})$ than at the long interval $(M=540 \mathrm{msec})$ $[F(1,47)=14.04, p<.001]$, but with the Proctor display, mean RT was shorter at the short interval $(M=527 \mathrm{msec})$ than at the long one $(M=551 \mathrm{msec})[F(1,47)=5.38, p<$ $.025]$. Additionally, the task-switch cost was larger at the short cuing interval (mean difference $[M D]=46 \mathrm{msec}$ ) than at the long one $(M D=26 \mathrm{msec})$. This task transition $\times$ cuing interval interaction was significant with the Meiran display (showing a 56-msec task-switch cost at the short interval, but only a 25 -msec cost at the long one) $[F(1,47)=17.20, p<.001]$, but not with the Proctor display (showing a 36-msec task-switch cost at the short interval, and a $27-\mathrm{msec}$ cost at the long one) $[F(1,47)=$ $2.58, p=.115]$. These patterns are similar to those obtained by Meiran (1996; Meiran et al., 2000) and Proctor et al. (2006), respectively.

Rule congruency entered into three separate two-way interactions with cuing interval, task transition, and cue dimension. The advantage for rule-congruent trials over rule-incongruent trials was larger at the short cuing interval $(M D=94 \mathrm{msec})$ than at the long one $(M D=$ $75 \mathrm{msec}$ ). The task-switch cost was larger for incongruent trials $(M D=44 \mathrm{msec})$ than for congruent trials $(M D=$ $27 \mathrm{msec}$ ). Moreover, when the rules were incongruent, the horizontal dimension showed a 44-msec advantage over the vertical dimension; but when the rules were congruent, there was no right-left prevalence effect $(M D=$ $0 \mathrm{msec}$ ). Another way of characterizing this interaction is that the difference between rule-incongruent and rulecongruent trials was larger when the cued dimension was vertical $(M D=104 \mathrm{msec})$ than when it was horizontal $(M D=65 \mathrm{msec})$.

Table 1

Results of ANOVAs for Reaction Time (RT) and Percentage Error (PE) of Experiment 1

\begin{tabular}{|c|c|c|c|c|c|c|}
\hline \multirow[b]{2}{*}{ Source } & \multicolumn{2}{|c|}{ RT } & \multicolumn{2}{|c|}{$\mathrm{PE}$} & \multicolumn{2}{|c|}{$\eta_{\mathrm{p}}^{2}$} \\
\hline & $F$ & $M S_{\mathrm{e}}$ & $F$ & $M S_{\mathrm{e}}$ & RT & $\mathrm{PE}$ \\
\hline Task transition (TT) & $125.84^{*}$ & 3,925 & $68.75^{*}$ & 6.91 & .572 & .426 \\
\hline Cue dimension (CD) & $31.47^{*}$ & 6,051 & $59.19^{*}$ & 13.68 & .251 & .386 \\
\hline Rule congruency (RC) & $249.70^{*}$ & 19,114 & $160.43^{*}$ & 25.95 & .727 & .631 \\
\hline Cue interval $(\mathrm{CI}) \times$ Display format $(\mathrm{DF})$ & $19.38^{*}$ & 32,913 & & & .171 & \\
\hline $\mathrm{TT} \times \mathrm{RC}$ & $20.67^{*}$ & 2,016 & $67.65^{*}$ & 7.39 & .180 & .418 \\
\hline $\mathrm{TT} \times \mathrm{CI}$ & $18.27^{*}$ & 2,148 & $5.52^{*}$ & 4.82 & .163 & .055 \\
\hline $\mathrm{TT} \times \mathrm{CI} \times \mathrm{DF}$ & $5.45^{*}$ & 2,148 & & & .055 & \\
\hline $\mathrm{CD} \times \mathrm{RC}$ & $94.53^{*}$ & 2,016 & $55.77^{*}$ & 12.13 & .501 & .372 \\
\hline $\mathrm{CD} \times \mathrm{CI}$ & & & $55.72^{*}$ & 5.02 & & .106 \\
\hline $\mathrm{CD} \times \mathrm{CI} \times \mathrm{DF}$ & & & $16.59^{*}$ & 5.02 & & .034 \\
\hline $\mathrm{RC} \times \mathrm{CI}$ & $19.58^{*}$ & 1,961 & & & .172 & \\
\hline $\mathrm{CD} \times \mathrm{RC} \times \mathrm{CI}$ & & & $11.80^{*}$ & 4.71 & & .112 \\
\hline
\end{tabular}


Iable 2

Mean Reaction Time (RT, in Milliseconds) and Percentage Error (PE) in Experiment 1, As a Function of Cue Dimension, Rule Congruency, Cuing Interval, Task Transition, and Display Format

\begin{tabular}{|c|c|c|c|c|}
\hline \multirow{3}{*}{$\begin{array}{c}\text { Task Transition } \\
\text { and Cue Dimension }\end{array}$} & \multicolumn{4}{|c|}{ Cuing Interval } \\
\hline & \multicolumn{2}{|c|}{ Short } & \multicolumn{2}{|c|}{ Long } \\
\hline & RT & PE & RT & PE \\
\hline
\end{tabular}

Meiran Display: Rule-Congruent Trials

Repetition

$\begin{array}{lllll}\text { Vertical } & 527 & 0.26 & 494 & 0.29\end{array}$

$\begin{array}{lllll}\text { Horizontal } & 526 & 0.07 & 504 & 0.00\end{array}$

Switch

$\begin{array}{lllll}\text { Vertical } & 573 & 0.12 & 518 & 0.19\end{array}$

$\begin{array}{lllll}\text { Horizontal } & 580 & 0.06 & 516 & 0.12\end{array}$

Meiran Display: Rule-Incongruent Trials

Repetition

$\begin{array}{lllll}\text { Vertical } & 631 & 4.39 & 584 & 3.28\end{array}$

$\begin{array}{lllll}\text { Horizontal } & 592 & 1.11 & 528 & 0.73\end{array}$

Switch

$\begin{array}{lllll}\text { Vertical } & 701 & 6.76 & 610 & 6.34\end{array}$

$\begin{array}{lllll}\text { Horizontal } & 647 & 2.96 & 566 & 3.30\end{array}$

Proctor Display: Rule-Congruent Trials

Repetition

$\begin{array}{lllll}\text { Vertical } & 474 & 0.26 & 499 & 0.08\end{array}$

$\begin{array}{lllll}\text { Horizontal } & 463 & 0.12 & 497 & 0.06\end{array}$

Switch

$\begin{array}{lllll}\text { Vertical } & 487 & 0.17 & 520 & 0.18\end{array}$

$\begin{array}{lllll}\text { Horizontal } & 489 & 0.07 & 518 & 0.07\end{array}$

Proctor Display: Rule-Incongruent Trials

Repetition

$\begin{array}{lllll}\text { Vertical } & 578 & 4.27 & 593 & 2.26\end{array}$

$\begin{array}{lllll}\text { Horizontal } & 522 & 1.10 & 562 & 1.21\end{array}$

Switch

$\begin{array}{lllll}\text { Vertical } & 622 & 6.11 & 627 & 5.10\end{array}$

$\begin{array}{lllll}\text { Horizontal } & 581 & 2.20 & 593 & 3.68\end{array}$

PE also showed no main effect of display format $(F<1)$. The main effects of task transition, cue dimension, and rule congruency were significant. PE was larger when the task switched $(M=2.3 \%)$ than when it repeated $(M=1.2 \%)$, when the cue dimension was vertical $(M=$ $2.5 \%)$ than when it was horizontal $(M=1.0 \%)$, and when the dimensions were rule incongruent $(M=3.4 \%)$ than when they were rule congruent $(M=0.1 \%)$.

Although there was no main effect of cuing interval, this variable entered into significant two-way interactions with task transition and cue dimension. The task-switch cost was smaller at the short cuing interval $(M D=0.86 \%)$ than at the long cuing interval $(M D=1.4 \%)$. In contrast, the benefit for the horizontal dimension over the vertical dimension was larger at the short cuing interval $(M D=$ $1.8 \%)$ than at the long cuing interval $(M D=1.1 \%)$.

The only other significant two-way interactions were those of rule congruency with task transition and cue dimension. The former indicates that the rule-congruency benefit was larger for task-switch trials $(M D=4.4 \%)$ than for task-repeat trials $(M D=2.2 \%)$, whereas the latter shows no right-left prevalence effect for congruent trials $(M D=$ $0.1 \%)$ but an effect for incongruent trials $(M D=2.8 \%)$. The latter was qualified by a three-way interaction of rule con- gruency and cue dimension with cuing interval, which was due primarily to the right-left prevalence effect for incongruent trials' being larger at the short cuing interval $(M D=$ $3.5 \%)$ than at the long cuing interval $(M D=2.1 \%)$.

\section{Discussion}

Overall, mean RT and PE did not differ significantly between the two display formats. Also, a task-switch cost, taskcongruency effect, and right-left prevalence effect were evident. With the Meiran display, mean RT was $57 \mathrm{msec}$ longer at the short cuing interval than at the long one, whereas with the Proctor display, mean RT was 24 msec shorter at the short cuing interval than at the long one. In comparing across the tasks, this difference is due primarily to mean RT being elevated by $70 \mathrm{msec}$ more at the short cuing interval for the Meiran display than that for the Proctor display. This outcome suggests that some aspect of the Meiran display requires extra processing time at the short cuing interval of $203 \mathrm{msec}$ that was used in this study.

The increase in mean RT at the long cuing interval with the Proctor display is not in agreement with the results of Proctor et al.'s (2006) Experiment 3, which was similar, except for the short and long cuing intervals being 100 and $900 \mathrm{msec}$, respectively. That experiment showed RT to be $37 \mathrm{msec}$ shorter at the long interval than at the short one, as did Proctor et al.'s (2006) Experiment 1, for which all trials were rule incongruent. However, Proctor et al.'s (2006) Experiment 2, for which all trials were also rule incongruent, but the short and long cuing intervals were 300 and $3,000 \mathrm{msec}$, did show $34 \mathrm{msec}$ longer RT at the long interval than at the short one. Examining across experiments, the primary factor contributing to these different result patterns seems to be that, with the Proctor display format, mean RT is about $35 \mathrm{msec}$ longer when the cuing interval is $100 \mathrm{msec}$ than when it is 200 or $300 \mathrm{msec}$, suggesting that preparation is greater after a few hundred milliseconds.

The task-switch cost showed a significant reduction at the long cuing interval, compared with that at the short one, with the Meiran display (31-msec reduction; see Figure 2). With the Proctor display, however, there was only a slight, nonsignificant tendency in the same direc-

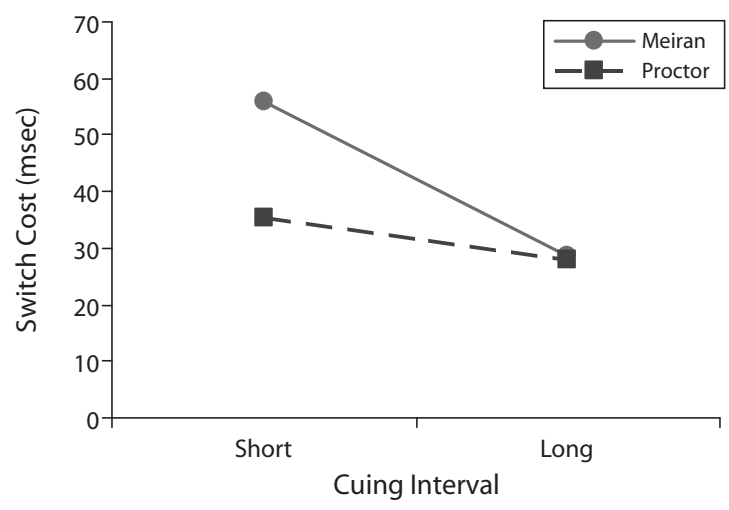

Figure 2. Plot of switch costs as a function of cuing interval (short, long) and display format (Meiran, Proctor) in Experiment 1. 
tion (9-msec reduction). The fact that a significant reduction in the task-switch cost at the long cuing interval was evident only with the Meiran display, and that this display also showed elevated RT at the short interval, suggests that the larger switch cost at the short interval may be a consequence of the processes that produce the elevated RT (see the General Discussion; see also Altmann, 2004).

A right-left prevalence effect of $22 \mathrm{msec}$ was obtained, but this benefit for cuing the horizontal dimension versus the vertical dimension did not depend on display format. Furthermore, it was evident only on rule-incongruent trials, as in Proctor et al.'s (2006) study, and there was no significant change of the prevalence effect across the two cuing intervals, even with the Meiran display. Thus, although Meiran's (1996; Meiran et al., 2000) results showed a tendency toward reduced right-left prevalence at long cuing intervals, that tendency was not evident in Experiment 1. However, although the RT data showed no significant influence of cuing interval on the right-left prevalence effect, the PE data showed a significantly smaller benefit for the horizontal dimension (i.e., a reduced right-left prevalence effect) at the long cuing interval.

\section{EXPERIMENT 2}

Experiments 2 and 3 were designed to dissociate several factors that differentiate the Meiran and Proctor display formats. In Experiment 2, we used only small displays of the type used by Meiran (1996) and manipulated two variables: cue type and cue offset. The cue types were side arrows, as used by Meiran, and centered arrows, as in Proctor et al.'s (2006) study. These cue types differ in whether the cue stimuli are presented peripherally (relative to the array) or centrally. Such cues that signal a single location are classified as being exogenous and endogenous, and are often described as drawing attention to the cued location automatically or through controlled processes, respectively (e.g., Funes, Lupiáñez, \& Milliken, 2007). If side cues, but not centered cues, attract attention to their locations automatically in the spatial task-switching paradigm, the different effects of cuing interval on RT and the task-switch cost for the two cue types should be apparent even when the display is small for all conditions. Such an outcome would suggest that the side cues capture attention when they appear, thereby slowing RTs and increasing task-switching costs at short cuing intervals.

Cue offsets included exposure of the cue only until onset of the target stimulus, as with Proctor et al.'s (2006) method, or, throughout the period in which the target stimulus was displayed, until the participant responded, as with Meiran's (1996; Meiran et al., 2000) method. The results from Experiment 1 suggest that if cue offset is crucial in the present context, RT and switch costs should decrease at the long cuing interval when the cue is displayed until the response, but not when it offsets at target onset. Such a finding might also be due to the side cues drawing attention to their locations, especially with brief presentation.

\section{Method}

Sixty-four new participants were recruited from the same pool as in Experiment 1. Sixteen performed in each of four conditions that varied in cue type and cue offset: after either the cue-target interval (CTI) or the cue-response interval (CRI). The displays were the same as those for the Meiran display format in Experiment 1, except for the cue manipulations. The condition with side cues and CRI cue offset was identical to the Meiran display condition in Experiment 1. A second condition used the side cues, but the cue remained on the screen only during the CTI, as in Proctor et al.'s (2006) study. The remaining two conditions used the centered cue (shrunk to $0.8 \mathrm{~cm}$ long, with arrowheads of $0.5 \mathrm{~cm}$ wide; see Figure 1C), with the cue staying on for only the CTI, as in Proctor et al.'s (2006) method, or throughout the CRI. In other respects, the method was similar to that of Experiment 1, unless otherwise indicated. Data were unintentionally not recorded for the first two trial blocks, and those blocks were treated as practice.

\section{Results}

We excluded $2.2 \%$ of the trials as outliers, using the criteria specified for Experiment 1. Mean correct RT and PE were submitted to separate six-factor ANOVAs (see Table 3): cue type (side, centered) and cue offset (CTI, CRI) were between-participants factors, and cue dimension (horizontal, vertical), task transition (repetition, switch), cuing interval (short, long), and rule congruency (congruent, incongruent) were within-participants factors (see Table 4 for means).

Table 3

Results of ANOVAs for Reaction Time (RT) and

Percentage Error (PE) of Experiment 2

\begin{tabular}{|c|c|c|c|c|c|c|}
\hline \multirow[b]{2}{*}{ Source } & \multicolumn{2}{|c|}{ RT } & \multicolumn{2}{|c|}{$\mathrm{PE}$} & \multicolumn{2}{|c|}{$\eta_{\mathrm{p}}^{2}$} \\
\hline & $F$ & $M S_{\mathrm{e}}$ & $F$ & $M S_{\mathrm{e}}$ & RT & PE \\
\hline Cue dimension (CD) & $15.99^{*}$ & 6,203 & $24.39^{*}$ & 19.81 & .210 & .289 \\
\hline Task transition (TT) & $38.14^{*}$ & 4,789 & $28.97^{*}$ & 11.19 & .389 & .326 \\
\hline Cuing interval (CI) & $7.97^{*}$ & 50,897 & & & .117 & \\
\hline Rule congruency (RC) & $108.28^{*}$ & 16,201 & $92.44^{*}$ & 26.97 & .643 & .606 \\
\hline $\mathrm{CD} \times \mathrm{CI} \times$ Cue type $(\mathrm{CT})$ & & & $4.45^{*}$ & 9.19 & & .069 \\
\hline $\mathrm{CD} \times \mathrm{RC}$ & $20.32^{*}$ & 3,459 & $24.60^{*}$ & 20.40 & .253 & .291 \\
\hline $\mathrm{TT} \times \mathrm{CI}$ & $38.75^{*}$ & 2,910 & & & .392 & \\
\hline $\mathrm{TT} \times \mathrm{RC}$ & & & $29.00^{*}$ & 10.00 & & .326 \\
\hline $\mathrm{CI} \times \mathrm{RC}$ & $21.70^{*}$ & 3,464 & & & .266 & \\
\hline $\mathrm{CD} \times \mathrm{TT} \times \mathrm{CI} \times \mathrm{CT} \times$ Cue offset & & & $4.00^{*}$ & 4.42 & & .063 \\
\hline $\mathrm{CD} \times \mathrm{TT} \times \mathrm{RC}$ & $4.10^{*}$ & 2,501 & & & .064 & \\
\hline $\mathrm{CD} \times \mathrm{CI} \times \mathrm{RC} \times \mathrm{CT}$ & & & $4.35^{*}$ & 9.32 & & .068 \\
\hline
\end{tabular}


Table 4

Mean Reaction Time (RT, in Milliseconds) and Percentage Error (PE) in Experiment 2, As a Function of Cue Dimension, Cue Offset, Rule Congruency, Cuing Interval, Task Transition, and Cue Type

\begin{tabular}{|c|c|c|c|c|c|c|c|c|}
\hline \multirow{3}{*}{$\begin{array}{c}\text { Task Transition } \\
\text { and Cue Dimension }\end{array}$} & \multicolumn{4}{|c|}{ CTI Cue Offset } & \multicolumn{4}{|c|}{ CRI Cue Offset } \\
\hline & \multicolumn{2}{|c|}{ Short Interval } & \multicolumn{2}{|c|}{ Long Interval } & \multicolumn{2}{|c|}{ Short Interval } & \multicolumn{2}{|c|}{ Long Interva } \\
\hline & RT & $\mathrm{PE}$ & RT & $\mathrm{PE}$ & RT & $\mathrm{PE}$ & RT & $\mathrm{PE}$ \\
\hline \multicolumn{9}{|c|}{ Side Cues: Rule-Congruent Trials } \\
\hline \multicolumn{9}{|l|}{ Repetition } \\
\hline Vertical & 497 & 0.00 & 492 & 0.00 & 505 & 0.23 & 480 & 0.00 \\
\hline Horizontal & 485 & 0.21 & 462 & 0.56 & 477 & 0.00 & 500 & 0.00 \\
\hline \multicolumn{9}{|l|}{ Switch } \\
\hline Vertical & 540 & 0.26 & 481 & 0.00 & 553 & 0.00 & 489 & 0.00 \\
\hline Horizontal & 533 & 1.07 & 480 & 0.26 & 536 & 0.27 & 496 & 0.42 \\
\hline \multicolumn{9}{|c|}{ Side Cues: Rule-Incongruent Trials } \\
\hline \multicolumn{9}{|l|}{ Repetition } \\
\hline Vertical & 575 & 3.66 & 555 & 1.85 & 583 & 2.73 & 557 & 2.36 \\
\hline Horizontal & 572 & 1.25 & 517 & 1.23 & 570 & 1.00 & 530 & 0.87 \\
\hline \multicolumn{9}{|l|}{ Switch } \\
\hline Vertical & 639 & 9.00 & 562 & 5.41 & 665 & 5.38 & 562 & 2.67 \\
\hline Horizontal & 617 & 4.01 & 511 & 2.53 & 614 & 3.08 & 539 & 3.15 \\
\hline \multicolumn{9}{|c|}{ Centered Cues: Rule-Congruent Trials } \\
\hline \multicolumn{9}{|l|}{ Repetition } \\
\hline Vertical & 459 & 0.48 & 472 & 0.25 & 521 & 0.50 & 513 & 0.39 \\
\hline Horizontal & 453 & 0.00 & 460 & 0.00 & 541 & 0.00 & 510 & 0.00 \\
\hline \multicolumn{9}{|l|}{ Switch } \\
\hline Vertical & 477 & 0.27 & 479 & 0.00 & 565 & 0.30 & 515 & 0.22 \\
\hline Horizontal & 472 & 0.54 & 474 & 0.00 & 582 & 0.00 & 527 & 0.00 \\
\hline \multicolumn{9}{|c|}{ Centered Cues: Rule-Incongruent Trials } \\
\hline \multicolumn{9}{|l|}{ Repetition } \\
\hline Vertical & 570 & 3.90 & 559 & 5.06 & 549 & 3.78 & 606 & 3.65 \\
\hline Horizontal & 512 & 1.73 & 493 & 0.27 & 643 & 1.17 & 601 & 0.99 \\
\hline \multicolumn{9}{|l|}{ Switch } \\
\hline Vertical & 616 & 7.42 & 568 & 6.98 & 724 & 4.31 & 637 & 7.06 \\
\hline Horizontal & 557 & 3.24 & 501 & 2.85 & 685 & 1.98 & 584 & 1.49 \\
\hline
\end{tabular}

Mean RT was similar for the side cues $(M=537 \mathrm{msec})$ and centered cues $(M=548 \mathrm{msec})(F<1)$, and no terms involving cue type or cue offset were significant. Thus, within chance limits, all effects were similar for the side and centered cue types, regardless of whether the cue offset occurred after the CTI or the CRI. Although the mean data in Table 4 suggest that the centered cues showed shorter RTs for the CTI offset than for the CRI offset, which the side cues did not, this interaction yielded an $F$ value less than 1 .

Main effects of task transition, cue dimension, and rule congruency were significant. Mean RT was 27 msec longer when the task switched $(M=556 \mathrm{msec})$ than when it repeated $(M=529 \mathrm{msec}), 20 \mathrm{msec}$ longer when the cue dimension was vertical $(M=552 \mathrm{msec})$ than when it was horizontal $(M=532 \mathrm{msec})$, and $83 \mathrm{msec}$ longer when the dimensions were rule incongruent $(M=584 \mathrm{msec})$ than when they were rule congruent $(M=501 \mathrm{msec})$. Thus, as in Experiment 1, typical task-switch, right-left prevalence, and rule-congruency effects were obtained.

There was also a main effect of cuing interval, with mean RT being $40 \mathrm{msec}$ longer at the short interval $(M=$ $562 \mathrm{msec})$ than at the long interval $(M=522 \mathrm{msec})$, as was found with Meiran's display in Experiment 1. Cuing interval entered into two-way interactions with task transition and rule congruency. At the short cuing interval, the cost for task-switch trials over task-repeat trials was $48 \mathrm{msec}$, but at the long cuing interval this cost was only $6 \mathrm{msec}$ (see Figure 3A). Similarly, there was a 100-msec benefit for rule-congruent trials over rule-incongruent trials at the short cuing interval, but only a 65 -msec benefit at the long cuing interval.

Cue dimension interacted with rule congruency. There was no right-left prevalence effect for rule-congruent trials $(M D=3 \mathrm{msec})$, but there was for the rule-incongruent trials $(M D=37 \mathrm{msec})$. These two factors also entered into a three-way interaction with task transition. The right-left prevalence effect was absent for congruent trials regardless of whether the task repeated $(M D=7 \mathrm{msec})$ or switched $(M D=-1 \mathrm{msec})$. For rule-incongruent trials, though, the right-left prevalence effect was larger when the task switched $(M D=46 \mathrm{msec})$ than when it repeated $(M D=26 \mathrm{msec})$. Another way of characterizing this interaction is that the task-switch cost was larger for the vertical dimension on rule-incongruent trials $(52 \mathrm{msec})$ than for the other combinations of dimension and rule congruency $(23 \mathrm{msec})$.

PE was similar for the side and centered cue conditions, and cue offset showed no significant effects. The main 

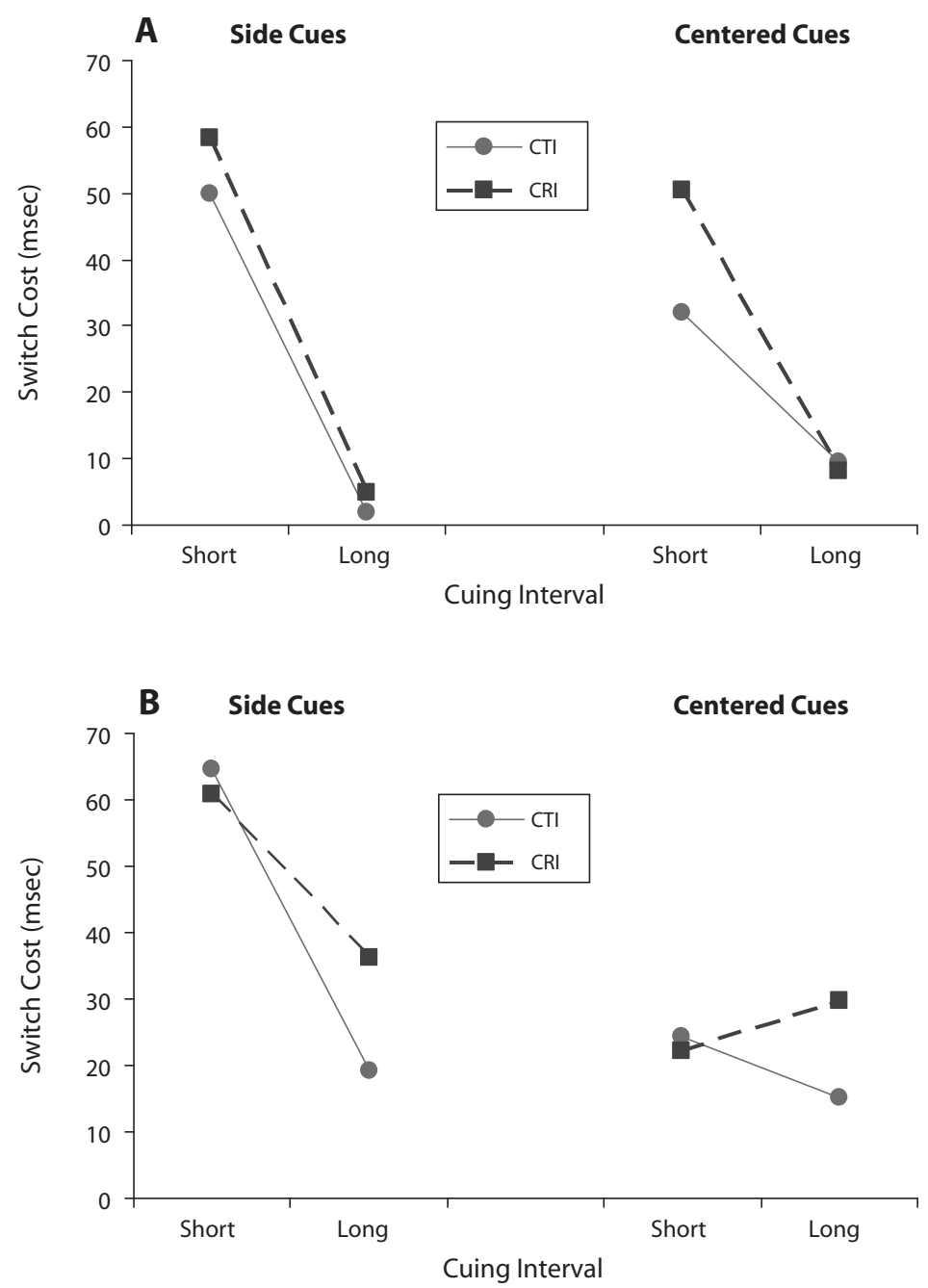

Figure 3. Plot of switch costs as a function of cuing interval (short, long) and cue offset (cue-target interval [CTI], cue-response interval [CRI]) for the side- and centeredcue conditions of Experiments 2 (panel A) and 3 (panel B).

effects of task transition, cue dimension, and rule congruency were significant. PE was larger when the task switched $(M=2.3 \%)$ than when it repeated $(M=1.2 \%)$, when the cue dimension was vertical $(M=2.4 \%)$ than when it was horizontal $(M=1.1 \%)$, and when the dimensions were rule incongruent $(M=3.3 \%)$ than when they were rule congruent $(M=0.2 \%)$. These differences are all consistent with the RT data.

Rule congruency entered into two-way interactions with task transition and cue dimension. There was no cost of task switch over task repetition for rule-congruent trials, but there was a $2.2 \%$ cost of task switch over task repetition for rule-incongruent trials. There was no right-left prevalence effect for rule-congruent trials, but there was a 2.8\% right-left prevalence effect for rule-incongruent trials.

The three-way interaction of cue dimension, cuing interval, and cue type (side vs. centered) was significant, as was the four-way interaction of those variables with rule congruency. For both cue types, there was little indication of right-left prevalence for rule-congruent trials (side cues, $M D=-0.3 \%$ at both short and long cuing intervals; centered cues, $M D=0.2 \%$ at both short and long cuing intervals). For rule-incongruent trials, though, the side and centered cues showed right-left prevalence effects of similar magnitude at the short cuing interval $(M D=$ $2.8 \%$ for both cue types). However, the prevalence effect decreased at the long interval for the side cues $(M D=$ $1.1 \%)$, but increased for the centered cues $(M D=4.3 \%)$.

Finally, the five-way interaction of all variables except rule congruency was significant. The best characterization of this interaction is as follows: With side cues, the right-left prevalence effect in PE was larger at the short interval than at the long interval, with this difference between intervals being larger on switch trials with CRI 
offset $(M D=1.67 \%)$ than for the other three combinations of the task transition and cue offset variables $(M D=$ $0.80 \%$ ). With centered cues, however, the prevalence effect was smaller at the short interval than at the long interval, with this difference being absent on repetition trials with CRI offset $(M D=-0.02 \%)$ and evident for the other three combinations of the task transition and cue offset variables $(M D=1.55 \%)$.

\section{Discussion}

The condition using side cues that remained visible until the participant responded was equivalent to the Meiran display condition in Experiment 1. The pattern of results closely replicated those from the earlier experiment, showing a relative decrease in $\mathrm{RT}$ at the long cuing interval when compared with the RT at the short one. There were no significant effects on RT involving cue type or cue offset: For all conditions, RT decreased when the cuing interval increased, as in the Meiran condition of Experiment 1. With the side cues used by Meiran, the results were in fact more similar when the cue remained on only for the CTI than when it remained on throughout the CRI. Working memory would seem to be required for maintaining the cued information with the CTI offset, because the cue did not remain present during processing of the target stimulus. That the data for the CRI offset were similar to those for the CTI offset with the side cues suggests that working memory was also involved to a similar extent when the cue remained present until a response was made. For the centered cues, the tendency for RT to decrease as cuing interval increased was more evident when the cue offset after the CRI than when it offset after the CTI; but when we performed an analysis of the centered cue conditions alone, all terms involving the cue-duration variable were still nonsignificant.

The task-switch cost was evident primarily at the short cuing interval and not at the long one. There was no significant interaction of this effect with the cue type and cue offset manipulations. Thus, when the displays were small (the size of those used by Meiran, 1996), there was a consistent pattern of the task-switch cost being reduced at the long cuing interval relative to the short one, regardless of the exact properties of the cue stimuli. This outcome is in agreement with that of Gotler and Meiran (2001), who found that the reduction in switch costs at longer cuing intervals with the Meiran display was at least as large when the cue was visible only until target onset as when the cue remained visible until the response was made.

A right-left prevalence effect was also evident: The horizontal dimension showed a 20 -msec RT benefit over the vertical dimension. This benefit was of similar magnitude for the four between-participants conditions formed from the combination of cue type and cue offset. As in Experiment 1 , the prevalence effect was evident only on trials for which the rules did not correspond, and was equally evident at the short and long cuing intervals.

Together, the results of Experiment 2 suggest the hypothesis that display format (i.e., size of display) may be the critical variable that accounts for most of the discrepancies observed in Meiran's (1996) study and in our ear- lier study (Proctor et al., 2006). We tested this hypothesis in Experiment 3.

\section{EXPERIMENT 3}

In Experiment 2, the small display format did not show significant differences between the side and centered cues, or between whether the cue offset occurred after the CTI or CRI, as were evident in Experiment 1. This result suggests that the larger displays used by Proctor et al. (2006) may account for the discrepancy in the effect of cuing on switch costs in Meiran's and Proctor's displays. To test this implication, we conducted Experiment 3 in a manner similar to Experiment 2, except that we used a large display format similar to that of the Proctor display of Experiment 1. The results of this experiment, relative to those of Experiment 2, provide some indication of whether display size plays a major role in the pattern of cuing benefits that is obtained.

\section{Method}

Sixty-four new participants were recruited from the same pool as in the previous experiments. Sixteen performed in each of four conditions that varied in cue type and cue offset. The displays were analogous to those in Experiment 2, but were expanded to $21.0 \mathrm{~cm}$ in width and $15.6 \mathrm{~cm}$ in height. Thus, the size was similar to that of the Proctor display format in Experiment 1; but unlike in Experiment 1, a visible grid was used, as in Experiment 2. The target stimuli were identical to those used in the Proctor display condition of Experiment 1 . The same cue manipulations as in Experiment 2 were tested. The condition with the centered cue (expanded to $1.6 \mathrm{~cm}$ long, with arrowheads of $1.5 \mathrm{~cm}$ wide; see Figure 4A) and CTI cue offset was identical to that of the Proctor display condition in Experiment 1. A second condition used the same centered cue, but the cue remained on throughout the CRI. The remaining two conditions used the side cues (expanded to $0.8 \mathrm{~cm}$ long, with an arrowhead of $1.5 \mathrm{~cm}$ wide; see Figure 4B), as in Meiran (1996), with the cue staying on for the CTI or the CRI. In other respects, the method was similar to that of Experiment 2, with the exception that data for Blocks 1 and 2 were recorded and analyzed.

\section{Results}

We excluded $3.2 \%$ of the trials as outliers, using the criteria specified for Experiment 1. Mean correct RT and PE were submitted to six-factor ANOVAs, as in Experiment 2 (see Tables 5 and 6).

Unlike in Experiment 2, the main effect of cue type (side vs. centered) was significant, and that of cue offset approached significance $[F(1,60)=3.13, p=.082]$. RT was longer with side cues $(M=627 \mathrm{msec})$ than with centered cues $(M=536 \mathrm{msec})$, and was longer when the cue offset occurred after the CTI $(M=613 \mathrm{msec})$ than when the cue remained on for the CRI $(M=550 \mathrm{msec})$. That the side cues yielded significantly longer RTs than the centered cues only in this experiment suggests that their more peripheral presentation with the larger displays is responsible for the slow responding.

The main effects of task transition, cue dimension, and rule congruency were significant. Mean RT was $34 \mathrm{msec}$ longer when the task switched $(M=598 \mathrm{msec})$ than when it repeated $(M=564 \mathrm{msec}), 25 \mathrm{msec}$ longer when the cue dimension was vertical $(M=594 \mathrm{msec})$ than when it was 
A

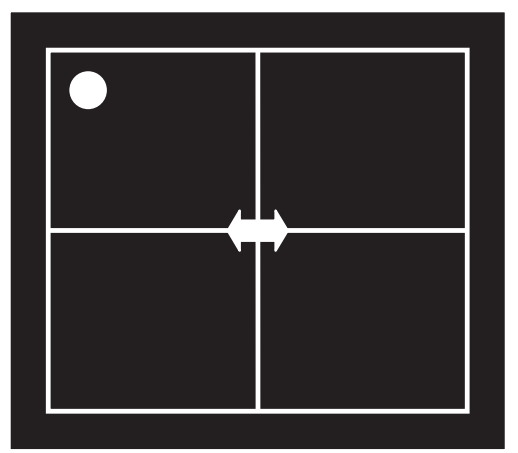

B

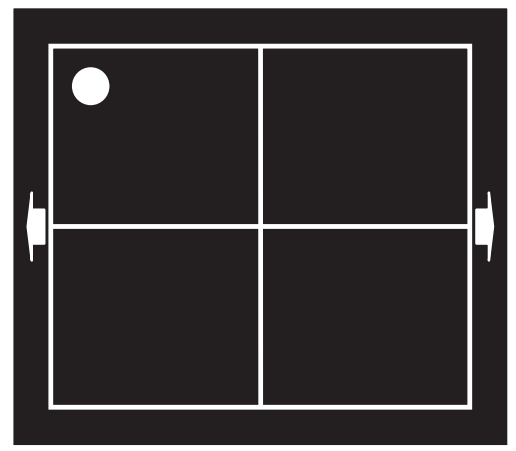

Figure 4. Illustration of the displays with a centered cue (A) and side cues (B) in Experiment 3. The displays were analogous to those used in Experiment 2, but were enlarged to cover the entire screen.

horizontal $(M=569 \mathrm{msec})$, and $99 \mathrm{msec}$ longer when the dimensions were rule incongruent $(M=631 \mathrm{msec})$ than when they were congruent $(M=532 \mathrm{msec})$. These effects are similar to those observed in Experiments 1 and 2.

There was also a main effect of cuing interval, with mean RT being $47 \mathrm{msec}$ longer at the short interval $(M=$ $605 \mathrm{msec})$ than at the long one ( $M=558 \mathrm{msec})$. Cuing interval entered into a two-way interaction with task transition. At the short interval, there was a 43 -msec task-switch cost, whereas at the long interval, the switch cost was only $26 \mathrm{msec}$.

Cuing interval interacted with cue type, and these two variables entered into a three-way interaction with cue offset. There was no reduction in mean RT at the long cuing interval with the centered cues $(F<1)$, but there was a 98 -msec reduction with the side cues $[F(1,30)=25.04$, $p<.001]$. The effect of cuing interval was larger for the CTI cue offset $(M D=150 \mathrm{msec})$ than for the CRI cue offset $(M D=46 \mathrm{msec})$ with the side arrow cues $[F(1,30)=$
7.04, $p=.013$ ], but it was numerically smaller for the CTI cue offset $(M D=-15 \mathrm{msec})$ than for the CRI duration $(M D=8 \mathrm{msec})$ with the centered arrow cues $(F<1)$.

Unlike in Experiment 2, cuing interval also entered into a three-way interaction with task transition and cue type, and the latter also showed a two-way interaction (see Figure $3 \mathrm{~B}$ ). The task-switch cost was larger with the side cues $(M D=45 \mathrm{msec})$ than with the centered cues $(M D=$ $23 \mathrm{msec}$ ). For the side cues, at the short cuing interval, the cost for task-switch trials was $69 \mathrm{msec}$, whereas at the long cuing interval, the cost was reduced to $32 \mathrm{msec}$. However, for the centered cues, the cost for task-switch trials over task-repeat trials at the short cuing interval $(M D=26 \mathrm{msec})$ was similar to that obtained at the long cuing interval $(M D=27 \mathrm{msec})$.

Cue dimension interacted with rule congruency, and these two variables entered into a three-way interaction with cuing interval. As in Experiments 1 and 2, for ruleincongruent trials, there was a 40 -msec right-left preva-

Table 5

Results of ANOVAs for Reaction Time (RT) and Percentage Error (PE) of Experiment 3

\begin{tabular}{|c|c|c|c|c|c|c|}
\hline \multirow[b]{2}{*}{ Source } & \multicolumn{2}{|c|}{ RT } & \multicolumn{2}{|c|}{$\mathrm{PE}$} & \multicolumn{2}{|c|}{$\eta_{\mathrm{p}}^{2}$} \\
\hline & $F$ & $M S_{\mathrm{e}}$ & $F$ & $M S_{\mathrm{e}}$ & RT & $\mathrm{PE}$ \\
\hline Cue type (CT) & $6.65^{*}$ & 323,920 & & & .100 & \\
\hline Cue dimension (CD) & $23.25^{*}$ & 7,027 & $41.33^{*}$ & 12.67 & .279 & .408 \\
\hline Task transition (TT) & $71.56^{*}$ & 4,164 & $35.08^{*}$ & 7.99 & .544 & .369 \\
\hline $\mathrm{TT} \times \mathrm{CT}$ & $7.67^{*}$ & 4,164 & & & .113 & \\
\hline Cuing interval (CI) & $16.65^{*}$ & 33,772 & & & .217 & \\
\hline $\mathrm{CI} \times \mathrm{CT}$ & $19.57^{*}$ & 33,772 & & & .246 & \\
\hline $\mathrm{CI} \times \mathrm{CT} \times$ Cue offset & $7.54^{*}$ & 33,772 & & & .112 & \\
\hline Rule congruency (RC) & $182.47^{*}$ & 13,933 & $158.14^{*}$ & 22.59 & .753 & .725 \\
\hline $\mathrm{CD} \times \mathrm{TT}$ & $4.37^{*}$ & 1,122 & & & .068 & \\
\hline $\mathrm{CD} \times \mathrm{CI}$ & & & $7.91^{*}$ & 6.97 & & .116 \\
\hline $\mathrm{CD} \times \mathrm{RC}$ & $17.27^{*}$ & 3,222 & $35.14^{*}$ & 12.62 & .223 & .369 \\
\hline $\mathrm{TT} \times \mathrm{CI}$ & $5.96^{*}$ & 3,396 & & & .090 & \\
\hline $\mathrm{TT} \times \mathrm{CI} \times \mathrm{CT}$ & $5.47^{*}$ & 3,396 & & & .083 & \\
\hline $\mathrm{TT} \times \mathrm{RC}$ & $17.69^{*}$ & 2,389 & $36.85^{*}$ & 8.54 & .228 & .380 \\
\hline $\mathrm{CD} \times \mathrm{CI} \times \mathrm{RC}$ & $7.41^{*}$ & 1,780 & $10.64^{*}$ & 6.81 & .110 & .151 \\
\hline $\mathrm{CD} \times \mathrm{CI} \times \mathrm{RC} \times \mathrm{CT}$ & & & $5.68^{*}$ & 6.81 & & .086 \\
\hline
\end{tabular}


Table 6

Mean Reaction Time (RT, in Milliseconds) and Percentage Error (PE)

in Experiment 3, As a Function of Cue Dimension, Cue Offset, Congruency, Cuing Interval, Task Transition, and Cue Type

\begin{tabular}{|c|c|c|c|c|c|c|c|c|}
\hline \multirow{3}{*}{$\begin{array}{c}\text { Task Transition } \\
\text { and Cue Dimension }\end{array}$} & \multicolumn{4}{|c|}{ CTI Cue Offset } & \multicolumn{4}{|c|}{ CRI Cue Offset } \\
\hline & \multicolumn{2}{|c|}{ Short Interval } & \multicolumn{2}{|c|}{ Long Interval } & \multicolumn{2}{|c|}{ Short Interval } & \multicolumn{2}{|c|}{ Long Interva } \\
\hline & RT & $\mathrm{PE}$ & RT & $\mathrm{PE}$ & RT & $\mathrm{PE}$ & RT & $\mathrm{PE}$ \\
\hline \multicolumn{9}{|c|}{ Side Cues: Rule-Congruent Trials } \\
\hline \multicolumn{9}{|l|}{ Repetition } \\
\hline Vertical & 680 & 0.00 & 563 & 0.19 & 541 & 0.21 & 514 & 0.61 \\
\hline Horizontal & 672 & 0.18 & 530 & 0.00 & 516 & 0.23 & 499 & 0.00 \\
\hline \multicolumn{9}{|l|}{ Switch } \\
\hline Vertical & 715 & 0.00 & 566 & 0.19 & 578 & 0.18 & 527 & 0.50 \\
\hline Horizontal & 717 & 0.00 & 552 & 0.00 & 570 & 0.34 & 514 & 0.00 \\
\hline \multicolumn{9}{|c|}{ Side Cues: Rule-Incongruent Trials } \\
\hline \multicolumn{9}{|l|}{ Repetition } \\
\hline Vertical & 794 & 6.20 & 672 & 4.15 & 628 & 4.81 & 566 & 3.23 \\
\hline Horizontal & 741 & 1.32 & 614 & 1.57 & 587 & 0.68 & 558 & 1.38 \\
\hline \multicolumn{9}{|l|}{ Switch } \\
\hline Vertical & 906 & 8.56 & 688 & 6.84 & 699 & 6.58 & 628 & 4.62 \\
\hline Horizontal & 807 & 2.41 & 650 & 4.28 & 668 & 1.93 & 613 & 4.64 \\
\hline \multicolumn{9}{|c|}{ Centered Cues: Rule-Congruent Trials } \\
\hline \multicolumn{9}{|l|}{ Repetition } \\
\hline Vertical & 490 & 0.36 & 519 & 0.20 & 463 & 0.00 & 475 & 0.18 \\
\hline Horizontal & 464 & 0.00 & 487 & 0.17 & 471 & 0.19 & 453 & 0.59 \\
\hline \multicolumn{9}{|l|}{ Switch } \\
\hline Vertical & 501 & 0.00 & 503 & 0.33 & 474 & 0.56 & 481 & 0.00 \\
\hline Horizontal & 498 & 0.00 & 514 & 0.00 & 489 & 0.00 & 477 & 0.00 \\
\hline \multicolumn{9}{|c|}{ Centered Cues: Rule-Incongruent Trials } \\
\hline \multicolumn{9}{|l|}{ Repetition } \\
\hline Vertical & 597 & 3.85 & 606 & 2.89 & 597 & 3.41 & 562 & 4.69 \\
\hline Horizontal & 557 & 2.23 & 574 & 2.30 & 537 & 1.25 & 534 & 1.20 \\
\hline \multicolumn{9}{|l|}{ Switch } \\
\hline Vertical & 619 & 6.75 & 636 & 5.20 & 617 & 6.20 & 604 & 6.37 \\
\hline Horizontal & 587 & 4.23 & 594 & 4.58 & 577 & 2.40 & 581 & 4.02 \\
\hline
\end{tabular}

Note-CTI, cue-target interval; CRI, cue-response interval.

lence effect; but for rule-congruent trials, there was little indication of right-left prevalence $(M D=11 \mathrm{msec})$. At the short cuing interval, the right-left prevalence effect was $49 \mathrm{msec}$ for incongruent trials, but only $6 \mathrm{msec}$ for congruent trials - a difference of $43 \mathrm{msec}$. At the long cuing interval, the right-left prevalence effect was $30 \mathrm{msec}$ for incongruent trials and $16 \mathrm{msec}$ for congruent trials - a difference of only $14 \mathrm{msec}$.

Task transition interacted with rule congruency as well. For rule-incongruent trials, the cost for task switch over task repetition was $55 \mathrm{msec}$, whereas for rule-congruent trials, the cost for task switch over task repetition was only 25 msec. Task transition also interacted with cue dimension, with the task-switch cost being larger for the horizontal dimension $(M D=39 \mathrm{msec})$ than for the vertical dimension $(M D=30 \mathrm{msec})$.

Neither cue type nor cue offset showed a main effect on PE $(F$ s $<1)$. The main effects of task transition, cue dimension, and rule congruency were significant. PE was larger when the task switched $(M=2.6 \%)$ than when it repeated $(M=1.5 \%)$, when the cue dimension was vertical $(M=2.8 \%)$ than when it was horizontal $(M=1.3 \%)$, and when the dimensions were incongruent $(M=3.9 \%)$ than when they were congruent $(M=0.2 \%)$.
Rule congruency entered into two-way interactions with task transition and cue dimension. For rule-incongruent trials, task-switch trials showed a $2.2 \%$ cost over taskrepetition trials, whereas for rule-congruent trials, there was no cost of task switch over task repetition. For ruleincongruent trials, there was a $2.8 \%$ right-left prevalence effect, whereas for rule-congruent trials, there was no right-left prevalence effect.

Cue dimension interacted with cuing interval, and these two variables entered into a three-way interaction with rule congruency. At the short interval, there was a $1.9 \%$ right-left prevalence effect, whereas at the long interval, the effect was only $1.1 \%$. For both short and long cuing intervals, there was no right-left prevalence effect for rule-congruent trials $(M D=0.1 \%$ and $0.2 \%$, respectively). However, for rule-incongruent trials, the right-left prevalence was larger at the short cuing interval than at the long one $(M D=3.8 \%$ and $1.8 \%$, respectively).

The only remaining significant effect was the four-way interaction of cue dimension, cue interval, cue type, and rule congruency. For rule-incongruent trials, the right-left prevalence effect was elevated at the short cuing interval $(M D=5.0 \%$ and $2.5 \%$ for side and centered cues, respectively) relative to the long one $(M D=-1.7 \%$ and $1.8 \%$ 
for side and centered cues, respectively), and relatively more still for the side cues than for the centered cues. For both cue types, PE showed no right-left prevalence effect for congruent trials at either the short $(M D=-0.1 \%$ and $0.2 \%$ for side and centered cues, respectively) or long $(M D=0.4 \%$ and $0.0 \%$ for side and centered cues, respectively) cuing interval for rule-congruent trials.

\section{Discussion}

The condition using centered cues that remained on only for the CTI was the same as the Proctor display condition in Experiment 1, except for the grid's being visible. The results replicate those of Experiment 1 fairly closely, showing RT to increase numerically at the long cuing interval relative to the short one. This pattern tended to be reduced, though nonsignificantly, when the centered cues were displayed throughout the CRI, similar to the tendency seen in Experiment 2. Thus, two factors appear to contribute to the pattern of increasing RT at the long cue interval obtained with the Proctor et al. (2006) conditions: the large display and the centered cue.

With the side cues, RT was longer at the short cuing interval than at the long one, regardless of the cue offset. Thus, neither the larger display size nor the termination of the cue at target onset seems to reduce the pattern of increased cuing benefit at long cue intervals for the side cues. Interestingly, the cue offset manipulation had the opposite effect with the side cues than with the centered cues. For the side cues, the decrease in RT at the long cuing interval was actually larger when the cue was visible only during the CTI than when it was visible until a response was made, the opposite of what would be expected if working memory load was higher when the cue offset at target onset than when it did not. This difference was not apparent with the small displays used in Experiment 2, which, as noted, implicates brief peripheral presentation of the side cues as the crucial factor.

The task-switch cost was larger at the short cuing interval than at the long one with the side cues, but there was no difference with the centered cues (see Figure 3B). Thus, whether the cues are presented centrally or peripherally is again implicated as an important factor. Out of the four data points involving the size of the cost for each cue type at the short and long cuing intervals, the only one that differs much from the other three is the data point for the side cues at the short interval, for which the task-switch cost was $66 \mathrm{msec}$, whereas the task-switch cost was approximately $30 \mathrm{msec}$ for the other conditions. This pattern of results suggests that extra processing is required by the side cues on switch trials, for which there was also some evidence in Experiment 1 (see the General Discussion).

The right-left prevalence effect did not depend on display format. Also, as in Experiments 1 and 2, the effect was primarily evident for rule-incongruent trials. Thus, whereas the switch cost is affected by display properties, the right-left prevalence effect is relatively insensitive to them. Unlike in Experiments 1 and 2, the right-left prevalence effect was smaller at the long cuing interval than at the short one for both RT and PE, although for the display condition equivalent to the Proctor display format of Experiment 1 (centered cues, CTI offset), there again was little influence of cuing interval on the right-left prevalence effect.

\section{GENERAL DISCUSSION}

With the display used by Meiran (1996) and colleagues to study task switching, RT was shorter and the task-switch cost smaller at the long cuing interval than at the short one, as was the case in their studies. With the display used by Proctor et al. (2006) to study the rightleft prevalence effect, RT was longer and the switch cost not significantly smaller at the long cuing interval than at the short one. Thus, the patterns of reduction and no reduction of task-switch costs at long cuing intervals in the respective studies were replicated. As noted, the finding of an increase in mean RT at the long cuing interval with the Proctor display format differs from the results of Proctor et al.'s (2006) Experiment 3, which was similar, except for the use of different short and long intervals: The intervals of Proctor et al.'s (2006) study were 100 and $900 \mathrm{msec}$, whereas those of the present study were 203 and $1,423 \mathrm{msec}$, respectively. Comparison of the results of the two experiments suggests that the difference in effects of cuing interval on RT is due mainly to mean RTs' being longer with the 100 -msec cuing interval than with the 203-msec interval. Such an outcome is not surprising, because general alertness typically increases during the first few hundred milliseconds following a warning signal (see, e.g., Meiran \& Chorev, 2005; Posner, Klein, Summers, \& Buggie, 1973). In neither experiment was the interaction of task transition and cuing interval significant, though, which is consistent with the difference in mean RTs' being due to the level of general alertness and not to the degree of preparation for the cued task (see, e.g., Meiran et al., 2000, Experiment 4).

The manipulations of display size, presentation of the cues at center or side locations, and whether the cue offset coincided with onset of the target stimulus or with the response to that stimulus in Experiments 2 and 3 showed that display size's interaction with cue type was the most important factor in producing the different effects of cuing interval on the task-switch cost. With small displays like those used by Meiran (1996), both centered and outer cue types showed the pattern of larger switch costs at the short cuing interval than at the long one. With large displays like those used by Proctor et al. (2006), the center cues showed no influence of cuing interval on the switch cost, but the outer cues did. Thus, use of a centered cue with the large display seems to be the main condition that results in a lack of cuing interval effect on switch costs.

Although the influence of cuing interval on the taskswitch cost depended on whether the Meiran or Proctor display format was used, the right-left prevalence effect was of similar magnitude for the two display formats and did not vary significantly as a function of cuing interval. Thus, with the Meiran display format, the apparent decrease in the right-left prevalence effect at longer cuing 
intervals in Meiran's (1996; Meiran et al., 2000) experiments was not evident. However, with the large display like that used by Proctor et al. (2006), the right-left prevalence effect was smaller at the long cuing interval than at the short one when the cues were located at the side of the display, or when centered cues remained visible until a response was made. Even in those cases, though, there was still a substantial right-left prevalence effect evident at the long interval. Thus, effortful grouping (Adam et al., 2003) of the stimulus and response sets along the vertical dimension, when it is cued, is able to overcome, within $1,423 \mathrm{msec}$, only a small part of the advantage for the horizontal dimension that arises from its higher saliency.

Although preparation interval had little influence on the right-left prevalence effect, there is evidence that the prevalence effect is dependent on having a task set in order to respond to the horizontal or vertical dimension. Nishimura and Yokosawa (2007, Experiment 1) used the Meiran display, but cued the relevant stimulus dimension by changing the color of the grid from white to red or green at a random interval of 0,170 , or $1,620 \mathrm{msec}$ before onset of the target stimulus. The right-left prevalence effects were of similar sizes to those of the present study at the cuing intervals of 170 and $1,620 \mathrm{msec}$, but at the 0 -msec interval, there was no prevalence effect. The absence of a right-left prevalence effect with a 0 -msec cuing interval is not surprising, given that the initial discovery of the prevalence effect occurred when the participants were instructed to respond on the basis of one dimension prior to a block of trials (see Rubichi et al., 2006) and that no prevalence effect is obtained for a two-dimensional Simon task, in which participants are prepared to respond to stimulus color and not location (Proctor, Vu, \& Nicoletti, 2003). Together, the results suggest that the rightleft prevalence effect is not a consequence of horizontal codes' being automatically activated more strongly than vertical codes, but to more efficient coding of the horizontal dimension when participants are set to respond to a location dimension.

One factor that does influence both the task-switch cost and the right-left prevalence is rule congruence: Both switch costs and right-left prevalence effects are larger on rule-incongruent trials than on rule-congruent trials. In the present study, the right-left prevalence effect was evident almost exclusively on rule-incongruent trials and was, for the most part, not affected by display format. This outcome implies that the advantage of the horizontal dimension occurs only in the presence of conflict between dimensions, even though participants did not know in advance of the target stimulus whether such conflict would be present. Therefore, our results indicate that the rightleft prevalence effect occurs only on trials for which selection between horizontal and vertical dimensions is necessary for performing the task accurately. Although the task-switch cost was smaller on rule-congruent trials than on rule-incongruent ones (e.g., Meiran et al., 2000), there was still a switch cost. Thus, even though the response is the same regardless of the task, having to switch between task sets seems to incur a cost, even when the current trial is rule congruent (see also Koch et al., 2003).
Basically, the results of the three experiments show that the modulation of the switch cost by cuing interval obtained by Meiran (1996, 2000; Meiran et al., 2000) depends on display format. It appears that at least part of this interaction is produced by elevated RT on switch trials at the short cuing interval when the display is small and/or the cues appear on the side. This result is consistent with Koch's (2001, Experiment 4) findings, which invites speculation that the reduction of switch costs resembles more of an increase of switch costs at short cuing intervals than a reduction of switch costs at long cuing intervals (see Altmann, 2004; Koch, 2001, for further discussion).

The advantage for the center cues at the short cuing interval with large displays suggests that spatial coding of stimulus locations may be easier in that situation than in the others. It is reasonable to assume that attention must be focused at the center of the display when the cue is presented at that location. With large displays, a shift of attention and possibly fixation to the target location is likely needed, which automatically produces a code of the target location relative to the cue location at target onset (Rizzolatti, Riggio, Dascola, \& Umiltà, 1987; Stoffer \& Umiltà, 1997). With the small display for both center and side cues, and with the large display for side cues, attention is likely distributed more globally, which requires effortful processing in order to prepare for the cued dimension. This analysis suggests that focused versus global mode of spatial attention may be the factor that leads to little influence of cuing interval on switch costs in the one case and significant effects in the other three cases.

Presumably, in the spatial task-switching paradigm, the residual switch costs at the long CTI are primarily due to the settings of attentional weights and their aftereffects (e.g., Meiran, 2000), or to involuntary retrieval of previous S-R episodes (e.g., Koch \& Allport, 2006; Waszak, Hommel, \& Allport, 2003). The right-left prevalence effect may be a close relative to the residual switch costs, because both seem to be consequences of the settings of attentional weights and are relatively unaffected by display properties that do not alter the salience of the horizontal dimension relative to the vertical one. In contrast, however, the fact that display type affected performance (i.e., switch costs) primarily at the short cuing interval suggests that it is the preparatory component of switch costs, as reflected by the cuing interval effect that is influenced by display factors. Thus, the cue-based "endogenous" preparation process appears to be much more vulnerable to exogenous factors than are the spatial coding processes on which the right-left prevalence effect is based.

Verbruggen et al. (2007) obtained evidence that cue offset can be a critical factor in task-cuing studies. They found that the residual task-switch cost typically obtained at long cuing intervals was eliminated when participants were forced to fully prepare for the task due to the cues' being presented briefly and then masked. Although our Experiment 2, which used small displays, did not show evidence of cue offset influencing the residual switch cost (see also Gotler \& Meiran, 2001), our Experiment 3, which used large displays, did. As can be seen in Figure 3B, at the long interval, the task-switch cost was only $17 \mathrm{msec}$ 
when the cue went off at target onset, but was $33 \mathrm{msec}$ when it remained on; however, this difference was not statistically significant $\left[F(1,60)=2.89, M S_{\mathrm{e}}=2,657, p=\right.$ .094]. Because Verbruggen et al.'s cues were presented for much shorter durations $(<100 \mathrm{msec})$ than ours and were followed by a pattern mask, any effect of cue offset on the residual switch cost in our study would be expected to be relatively weak. Moreover, Verbruggen et al. had participants switch between numerical tasks (i.e., parity vs. magnitude judgment) that require semantic retrieval processes, whereas our tasks comprised spatial judgments that require spatial coding and shifts in spatial attention. It remains to be seen whether larger effects of the cue offset variable in the spatial cuing paradigm are obtained with very brief, masked cue presentations, or whether differences in the effect of cue duration across the present study and the Verbruggen et al. study are primarily due to the nature of the tasks used.

To summarize, the present data suggest that display size and cue type interact in the spatial cuing paradigm used to study task switching. This interaction supports the idea that cuing effects on task-switch costs are quite sensitive to several variations in experimental setup. For example, several studies reported strong modulations in the size of cuing effects, and these studies examined the influence of a variety of factors, such as cue offset (Verbruggen et al., 2007), type of design to manipulate cuing (i.e., withinparticipants vs. between-participants; see, e.g., Altmann, 2004; Koch, 2001, 2005), whether preparation is afforded either by manipulating preparation time (i.e., cuing interval) or sequential task predictability (e.g., Koch, 2005), and the stress imposed on participants (e.g., Steinhauser, Maier, \& Hübner, 2007). Note that these studies used a variety of experimental tasks and paradigms. Hence, the present finding that preparatory reduction of switch costs on spatial judgment tasks is not robust across variations in display characteristics can probably be extended to other paradigms as well.

Based on the sum of the present findings and those reported in other studies, it appears that the cue-based preparatory reduction of switch costs is a more elusive phenomenon than previously thought. Although such preparation effects have often been taken as indicating the contribution of cognitive control in task switching (Monsell, 2003), the observed variability in cuing effects on switch costs suggests that this interaction is probably not an optimal empirical marker for indicating the influence or contribution of cognitive control processes. This suggestion may also be extended to recent discussions on the role of cue processing in task switching, as specified in models proposed by Logan and colleagues (e.g., Logan \& Bundesen, 2003; Schneider \& Logan, 2005). Particularly, it appears that cue repetition benefits are determined in an even more complex manner than typically assumed, even though there might be ways of accommodating the models to these effects of display characteristics.

Although the pattern of switch costs is relatively sensitive to display format, cue type, and cuing interval, the right-left prevalence effect is not. This difference in the pattern of interactive effects indicates that the prevalence effect is due to processes involving the ease of selecting a response on one dimension or the other, independent of processes involved in switching between tasks.

\section{AUTHOR NOTE}

We thank Erik Altmann, Alex Gotler, Michael Kane, and an anonymous reviewer for insightful comments on an earlier version of the manuscript. Correspondence concerning this article should be addressed to R. W. Proctor, Department of Psychological Sciences, Purdue University, West Lafayette, IN 47907 (e-mail: proctor@psych.purdue.edu).

\section{REFERENCES}

Adam, J. J., Hommel, B., \& Umiltà, C. (2003). Preparing for perception and action (I): The role of grouping in the response-cuing paradigm. Cognitive Psychology, 46, 302-358.

Altmann, E. M. (2004). The preparation effect in task switching: Carryover of SOA. Memory \& Cognition, 32, 153-163.

Altmann, E. M. (2006). Task switching is not cue switching. Psychonomic Bulletin \& Review, 13, 1016-1022.

Funes, M. J., Lupiáñez, J., \& Milliken, B. (2007). Separate mechanisms recruited by exogenous and endogenous spatial cues: Evidence from a spatial Stroop paradigm. Journal of Experimental Psychology: Human Perception \& Performance, 33, 348-362.

Gade, M., \& Koch, I. (2007). Cue-task associations in task switching. Quarterly Journal of Experimental Psychology, 60, 762-769.

Gotler, A., \& Meiran, N. (2001). Cognitive processes underlying a frontally mediated component of task switching. Brain \& Cognition, 47, 142-146.

Hommel, B. (1996). No prevalence of right-left over top-bottom spatial codes. Perception \& Psychophysics, 58, 102-110.

KосH, I. (2001). Automatic and intentional activation of task sets. Journal of Experimental Psychology: Learning, Memory, \& Cognition, 27, 1474-1486.

KocH, I. (2005). Sequential task predictability in task switching. Psychonomic Bulletin \& Review, 12, 107-112.

Koch, I., \& Allport, A. (2006). Cue-based preparation and stimulusbased priming of tasks in task switching. Memory \& Cognition, 34, 433-444.

Koch, I., Ruge, H., Brass, M., Rubin, O., Meiran, N., \& Prinz, W. (2003). Equivalence of cognitive processes in brain imaging and behavioral studies: Evidence from task switching. NeuroImage, 20, 572-577.

Logan, G. D., \& Bundesen, C. (2003). Clever homunculus: Is there an endogenous act of control in the explicit task-cuing procedure? Journal of Experimental Psychology: Human Perception \& Performance, 29, 575-599.

MAYR, U., \& KLIEGL, R. (2003). Differential effects of cue changes and task changes on task-set selection costs. Journal of Experimental Psychology: Learning, Memory, \& Cognition, 29, 362-372.

MEIRAN, N. (1996). Reconfiguration of processing mode prior to task performance. Journal of Experimental Psychology: Learning, Memory, \& Cognition, 22, 1423-1442.

MeIran, N. (2000). Reconfiguration of stimulus task sets and response task sets during task switching. In S. Monsell \& J. Driver (Eds.), Control of cognitive processes: Attention and performance XVIII (pp. 377-399). Cambridge, MA: MIT Press.

Meiran, N., \& Chorev, Z. (2005). Phasic alertness and the residual task-switching cost. Experimental Psychology, 52, 109-124.

Meiran, N., Chorev, Z., \& SaPIR, A. (2000). Component processes in task switching. Cognitive Psychology, 41, 211-253.

Monsell, S. (2003). Task switching. Trends in Cognitive Sciences, 7, 134-140.

Nicoletti, R., \& Umiltà, C. (1984). Right-left prevalence in spatial compatibility. Perception \& Psychophysics, 35, 333-343.

Nicoletti, R., \& Umiltà, C. (1985). Responding with hand and foot: The right/left prevalence in spatial compatibility is still present. Perception \& Psychophysics, 38, 211-216.

Nishimura, A., \& YoKosawa, K. (2007). Preparation for horizontal or 
vertical dimensions affects the right-left prevalence effect. Perception \& Psychophysics, 69, 1242-1252.

Posner, M. I., Klein, R., Summers, J., \& Buggie, S. (1973). On the selection of signals. Memory \& Cognition, 1, 2-12.

Proctor, R. W., KосH, I., \& VU, K.-P. L. (2006). Effects of precuing horizontal and vertical dimensions on right-left prevalence. Memory \& Cognition, 34, 949-958.

Proctor, R. W., Vu, K.-P. L., \& Nicoletti, R. (2003). Does right-left prevalence occur for the Simon effect? Perception \& Psychophysics, 65, 1318-1329.

Rizzolatti, G., Riggio, L., Dascola, I., \& Umiltà, C. (1987). Reorienting attention across the horizontal and vertical meridians: Evidence in favor of a premotor theory of attention. Neuropsychologia, 25, 31-40.

Rogers, R. D., \& Monsell, S. (1995). Costs of a predictable switch between simple cognitive tasks. Journal of Experimental Psychology: General, 124, 207-231.

Rubichi, S., Vu, K.-P. L., Nicoletti, R., \& Proctor, R. W. (2006). Spatial coding in two dimensions. Psychonomic Bulletin \& Review, 13, 201-216.

SchneIder, D. W., \& Logan, G. D. (2005). Modeling task switching without switching tasks: A short-term priming account of explicitly cued performance. Journal of Experimental Psychology: General, 134, 343-367.

Steinhauser, M., MaIer, M., \& HüBnER, R. (2007). Cognitive control under stress: How stress affects strategies of task-set reconfiguration. Psychological Science, 18, 540-545.

Stoffer, T. H., \& Umiltà, C. (1997). Spatial stimulus coding and the focus of attention in S-R compatibility and the Simon effect. In B. Hommel \& W. Prinz (Eds.), Theoretical issues in stimulus-response compatibility (pp. 181-208). Amsterdam: North-Holland.

Verbruggen, F., Liefooghe, B., Vandierendonck, A., \& Demanet, J. (2007). Short cue presentations encourage advance task preparation: A recipe to diminish the residual switch cost. Journal of Experimental Psychology: Learning, Memory, \& Cognition, 33, 342-356.

Vu, K.-P. L., \& Proctor, R. W. (2001). Determinants of the right-left and top-bottom prevalence for two-dimensional spatial compatibility. Journal of Experimental Psychology: Human Perception \& Performance, 27, 813-828.

Vu, K.-P. L., \& Proctor, R. W. (2002). The prevalence effect in twodimensional stimulus-response compatibility is a function of the relative salience of dimensions. Perception \& Psychophysics, 64, 815-828.

WaszaK, F., Hommel, B., \& Allport, A. (2003). Task-switching and long-term priming: Role of episodic stimulus-task bindings in taskshift costs. Cognitive Psychology, 46, 361-413.

(Manuscript received June 22, 2007; revision accepted for publication March 10, 2008.) 